\title{
Palabras de presentación del número diez de la Revista Derechos en Acción
}

\author{
E. Raúl Zaffaroni ${ }^{1} \mid$ Universidad de Buenos Aires
}

Revista Derechos en Acción ISSN 2525-1678/ e-ISSN 2525-1686

Año 4/No 12 Invierno 2019 (21 junio a 20 septiembre), 711-721

DOI: https://doi.org/10.24215/25251678e323

Queridas amigas amigos... me gusta hablar parado pero tener este aparato en la mano va a ser un inconveniente.

Realmente el número diez de esta revista es un milagro. Ya podríamos decir que se trata de un clásico. Que una revista jurídica dure diez números, con este volumen, con este trabajo -alguna idea tengo de lo que significa este trabajo- no solo intelectual sino el trabajo material.

Hoy en día las revistas jurídicas las editoriales las publican como publicidad...no como fuente de recursos...si detrás de una revista hay una empresa prácticamente sabemos que la vida es corta, uno o dos ejemplares y terminó la revista. Y están pasando cosas raras en el mundo académico, con lo cual tenemos que tener cuidado...cosas realmente extrañas. De repente una revista pide artículos que ofrece la página de la revista pero al mismo tiempo que uno le mande 300 o 400 dólares. Hay cosas extrañas.

Hay producción en serie, producción para curricular en algunos países de nuestra región se pagan las ediciones de libros, que no sé si los escriben los autores que aparecen en las ediciones. Porque hoy más de 100 páginas son un libro y menos

\footnotetext{
1 Profesor de Derechos Penal de la Universidad de Buenos Aires. Ex convencional constituyente en la Reforma de la Constitución Nacional de 1994, ex Ministro de la Corte Suprema de Justicia de la Nación y actual juez de la Corte Interamericana de Derechos Humanos.
} 
de 100 páginas es un folleto. Entonces el libro tiene 110 páginas y hay sellos editoriales que venden su sello con tal de que se les pague la edición. Con que se les pague la edición se consideran satisfechos, después todo lo que vendan puede ser ganancia.

Estas cosas están opacando la función de la academia, la función de la investigación se confunden investigaciones con trabajos de esta naturaleza y realmente cuando uno ve una producción de esta calidad no está todo perdido, todo lo otro sí, sabemos que hay negocio detrás (ipero de repente uno ve cosas como estas y le sube el ánimo!), que hay excursiones pretendidamente académicas, sabemos que hay quienes organizan viajes turísticos con alguna conferencia para después firmar papelitos. En fin, toda esa miseria toda esa mezquindad que se está generando en torno de lo académico. Pero de repente uno ve una cosa de estas. Y realmente sí, los felicito por el esfuerzo... y los felicito también por el título "Derechos en Acción”. ¿Y la acción qué puede ser en materia de derechos? Y... la acción no puede ser otra cosa que lucha. La acción en derecho es lucha. No se puede ser neutral en esto, en materia de derecho siempre se es partisano de alguna manera. Esto que decía ya, el propio sistematizador de la dogmática Jurídica, lo decía, Rudolph Von Ihering. Nada menos que el sistematizador de las reglas de la dogmática. Las había sistematizado en el derecho privado, con analogías con la química, etc. Y en su última etapa terminó diciendo el derecho es lucha (Der Kampf ums Recht).

$\mathrm{Si}$, los derechos se consiguen luchando, pero hay algunos que los heredan como algunos heredan la fortuna de los padres que la hicieron, de los abuelos y como no la lucharon la subestiman y la despilfarran.

Y en nuestra región, en el Sur (no el sur geográfico porque también sabemos que en el norte hay un Sur, aunque sean distintos, y en el Sur también hay un pequeño Norte). Pero desde la perspectiva del Sur, la lucha debe ser más clara y más decidida, tenemos que tener las ideas más claras. A veces no las tenemos. 
Recién se acordaba el Decano, de una discusión de hace unos cuantos años... ¿Dónde está el dolo? Efectivamente, lo que se estaba subestimando era una cuestión de construcción jurídica desde una teoría del conocimiento.

En lo personal, siempre me había chocado la acción un tanto deletérea de todas las teorías del conocimiento idealistas en el campo del derecho. Y fundamentalmente, me chocaba o no podía entender, la metodología neokantiana básicamente la idea de que el mundo existe pero es caótico y es el valor el que lo tiene que ordenar. Cuando uno les preguntaba a los neokatianos ¿qué es el valor? Y decían "los valores no son, los valores valen”. La pregunta siguiente era ¿Para quién valen? Y generalmente valen para el poder, claro. Eso era algo que me hacía ruido siempre, y si efectivamente, cuando en aquél momento no estábamos discutiendo dónde estaba el dolo, lo que estábamos discutiendo era: el neokatismo o el realismo, en definitiva era eso lo que discutíamos.

Welzel, en definitiva, era un conservador democristiano, no un hombre del pensamiento de la reconstrucción alemana de la época inmediatamente posterior a la Segunda Guerra, de modo que se había ido para el lado Aristotélico y recuperaba, la teoría por él llamada "de las estructuras lógicos reales” ¿qué quería decir? quería decir que el derecho tiene límites y la invención de conceptos jurídicos no es libre. Si, los valores se pueden elegir, perfecto, qué es lo bueno qué es lo malo, se puede elegir. Pero cuando se designa a un ente el derecho tiene que respetar la estructura óntica del ente según el orden al que pertenezca: zoológico, geográfico, biológico, económico, etc.

Cuando tengo que graficar, lo he escrito varias veces, disculpen quienes me han escuchado decirlo (lo reitero siempre), digo que no está prohibido que el derecho invente el lobo jurídico, la vaca jurídica y a la vaca jurídica la defina como un perro negro que aulla en la estepa. Si fenómeno, lo que pasa es que va a mandar al juez a ordeñar al lobo - con todas las consecuencias que va a tener para el juez-, nosotros hacemos saber jurídico 
¿para qué? tiene unos objetivos prácticos, queremos bajarle línea a los jueces. La aspiración es que eso se convierta en jurisprudencia, se convierta en decisiones de jueces, ¿y las decisiones de los jueces qué son? Son sentencias, y las sentencias ¿qué son? Son actos de gobierno, son actos de gobierno de la polis. Sin lugar a dudas... "Ah...no hay un poder que es apolítico" ¿pero qué me estas diciendo? Cómo va a haber un ejercicio de poder, una rama de gobierno de la polis que sea apolítica... podrá ser apartidista, pero "apolítica" no puede ser nunca. ¿Por qué? porque es una rama de gobierno que ejerce actos de gobierno, con algunas particularidades técnicas, sí... perfecto, pero son actos de gobierno y son actos políticos. De modo que cada proyecto dogmático que hacemos en el campo del derecho, es un proyecto político.

Un proyecto político no se puede hacer sin tomar en cuenta los datos de la realidad social, es inevitable. De la realidad social es inevitable... de la realidad social, económica, política, etc. de una sociedad, sino un programa político que no toma en cuenta eso o es un programa esquizofrénico o es un programa suicida directamente. Y sí, me fui convenciendo realmente de que la metodología idealista la metodología neokantiana, la percepción del mundo como un desorden que sólo ordena el valor, el valor puede ordenar lo que le da la gana y dejar fuera lo que le da la gana (incluso aunque deje afuera varios millones de muertos como en la Segunda Guerra Mundial) esto realmente no funciona.

Vivimos una ciencia juridica, un saber jurídico, si quieren llámenle ciencia, no importa - después de todo la definición de ciencia también depende del poder-. Vivimos un saber jurídico importado en gran medida. Nuestro saber jurídico se ha nutrido originariamente, sí, del derecho constitucional norteamericano por un lado, y el resto del derecho lo importamos de Europa y tuvimos contradicciones enormes porque fíjense que trajimos las doctrinas Europas a nuestro Rio de La plata (en la segunda mitad del siglo XIX, y a lo largo de casi todo el siglo 
pasado). Pero, en tanto que nosotros por haber copiado y mal copiado - y también arruinado en gran medida- la constitución de Estados Únicos, y aunque sea teóricamente tener control de constitucionalidad. Importamos las teorías jurídicas de una Europa que no conocía el control de constitucionalidad.

Es decir, formalmente - por lo menos- nosotros tenemos una estructura de estado constitucional de derecho y trajimos nuestras doctrinas jurídicas de Estados legales de derecho -alguien ha dicho, quizá exagerando un poco la nota- que Europa no tuvo derecho constitucional hasta la última Posguerra, que sólo tenía derecho administrativo ( es un poco exagerado, pero en gran medida es cierto).

Es verdad, los tribunales constitucionales europeos, si bien tienen algunos antecedentes en la época de entreguerras, lo tuvo la Constitución de Austria de Kelsen de 1921, etc. Pero muy poquitos, realmente el control de constitucionalidad de Europa, se desarrolla con los tribunales constitucionales de poder. Y algunos países que todavía no lo tienen, y tienen el control previo - los que son más o menos tributarios del Código Napoleón-. Inglaterra tampoco lo tiene, por supuesto, el Tribunal Europeo hace un sucedáneo el control de constitucionalidad, por un control de convencionalidad.

Y eso produjo cierta contradicción en nuestra labor juridica. Hemos dado un exceso de valor ritual a la ley infraconstitucionalidad. Y nos hemos olvidado, muchas veces de la necesidad de hacer valer predominantemente la norma constitucional, ba habido un exceso de respeto ritual por la ley infraconstitucional en desmedro del valor de la norma constitucional. Y cuando eso sucede, nos encontramos con impunidad en la violación del derecho o retrocesos en la acción o la lucha por el derecho.

Creo que debemos estar muy atentos cuando se redacta una constitución - y en eso estar muy alertas- de que no sólo no es suficiente, sino que puede resultar absurda la consagración de derechos en la constitución, si al mismo tiempo no se establece una estructura de poder que haga factible la exigibilidad de los 
derechos que se establecen en la constitución porque de lo contrario eso se convierte en una burla, es decir es una manifestación e buena voluntad que queda librada al deseo del señor de turno.

Creo que en gran medida nos ha pasado eso, en alguna medida hemos descuidado la estructura judicial, hemos descuidado poner más atención en la estructura de nuestro poder judicial. Y poner más atención en la importancia de nuestro control de constitucionalidad. Hoy tenemos un control de constitucionalidad muy débil, muy frágil y al mismo tiempo tenemos una estructura del Poder Judicial, absolutamente absurda. Gran parte de las dificultades que estamos teniendo son resultado de esto, es decir de una mala programación constitucional del Poder Judicial.

Esta importación de teorías, de doctrinas de Europa, se ha ido cubriendo con el manto de la simplificidad, es decir traemos doctrinas jurídicas importadas y las consagramos como ciencia neutral, políticamente neutral, ideológicamente neutral. Es decir, nos convertimos en científicos a través de una pretendida neutralidad ideológica y política. Y en eso, sobre todo después de la Segunda Guerra Mundial, en que la física había tomado una fuerza enorme en la vida cotidiana por las consecuencias que había, la energía nuclear etc. Cundió por todo los saberes lo que se llamaba fisicalismo. Cualquier ciencia debía tener una estructura análoga a la de la física, nosotros también la inventamos, una estructura análoga de la física - por supuesto que eso nos va a dar a los juristas la condición de científicos y nos permitía sentarnos en los consejos universitarios al lado de los cultores de las ciencias duras, etc-.

Pero en la realidad de los hechos es que de ninguna manera las teoría que traíamos de esos países habían sido, ideológicamente asépticas, apolíticas, etc. Sino que por el contrario, habían nacido conforme a las circunstancias de cada sociedad en cada uno de sus momentos históricos.

La pretensión de cientificidad nos jugó una mala pasada - y en alguna medida nos la sigue jugando hasta hoy-, tramos 
doctrinas, teorías, construcciones dogmáticas importadas, como si fueran construcciones técnicas en las que las posteriores van superando tecnológicamente a las anteriores.

Yo me dedico al derecho penal - como ustedes saben, a esa ciencia exótica- y lo veo esto con una claridad tremenda, la dogmática penal ha tenido un desarrollo enorme, y hemos venido importando de Alemania teorías como si trajésemos los sucesivos modelos de la Volkswagen (tiene mejores frenos, mejor calefacción, aire acondicionado, etc.). Pero nunca se nos ocurrió preguntarnos cuándo los alemanes habían inventado alguna de esas construcciones dogmáticas, y en realidad si... discutíamos dónde estaba el dolo. Pero ¿y por qué? a veces estaba por decirle a los estudiantes, ustedes van a abrir un libro y se van a encontrar con una serie de nombres alemanes en el medio y van a decir ¿qué diablos tiene esto? Y esto que pasa acá pasa en toda América Latina - no les digo España, que directamente está colonizada por la teoría Alemana-. Pero en América Latina pasa, cualquier país (puede ser Méjico, Ecuador, puede ser Brasil, nosotros, Paraguay).

¿Pero qué tiene que ver Alemania con América Latina? Bueno, hay una explicación de esto por qué las trajimos, fue mucho más dramático en el derecho penal que en otras ramas del saber jurídico. Porque nuestro derecho penal se nutrió, durante décadas, y diría que hasta mediados del siglo pasado se nutrió de lo que se llamó positivismo criminológico.

Positivismo criminológico, no es nada más ni nada menos que racismo - reduccionismo biologista y racismo- es decir una atribución de etiología biológica, por inferioridad biológica al crimen; el crimen no era objeto de estudio, el objeto de estudio era el criminal, porque era un bicho diferente - inferior a todo el resto de la población-. Naturalmente El más taquillero de todos estos autores era Lombroso, pero no era Lombroso sólo. En aquél momento en Europa, prácticamente lo sostenía todo el mundo. Es decir, que lo que los Europeos sostenían era que en medio de ellos -la raza superior-, de repente, alguien nacía con 
características de colonizado - las razas inferiores colonizadas: africanoides o mongoloides). Porque la filogenia y la ontogenia, resume la filogenia, entonces nacían "mal terminados" (sin el último golpe que tienen los civilizados).

Esto que no era más que el marco jurídico del spencerianismo, lo importan -lo importamos- en América Latina, se traduce en la práctica, en un acuerdo de corporaciones: La policía -que es una corporación relativamente nueva... todos piensan que la policía existió siempre (como la milanesa con papa fritas), no... la policía aparece a fines del siglo XVIII a comienzos del siglo XIX, hasta entonces no existía. Pero va tomando forma como un proceso de concentración urbana europeo, se concentra en las ciudades riqueza, se concentra miseria, todo eso es una situación explosiva y los europeos llevan la táctica de ocupación policial territorial de la colonia, la llevan a la metrópoli y empiezan a controlar a los colonizados de los suburbios de la metrópoli con la misma institución que controlaba a la colonia - una colonia no es más que un inmenso campo de ocupación policial territorial, no es otra cosa-.

Los suburbios, las grandes urbes metropolitanas europeas empiezan a ser controlados de la misma manera, pero la policía no tiene discurso y un poder sin discurso no se mantiene. Todo poder necesitar ser legitimado por un discurso. Alguien dijo que los que están en el poder necesitan soldados, pero también necesitan aguardiente, chicharrón y también el discurso. El discurso se lo facilita una corporación - que tenía muchas ganas de apropiarse de la cuestión penal- pero no habían tenido la oportunidad: los médicos. Entonces se hace una simbiosis entre los médicos y la policía, y son los médicos policiales, los médicos forenses los que empiezan a hablar del criminal nato y todas esas cosas. Todo ese racismo llega a América Latina, empalma muy bien con la ideología spenceriana de todas nuestras oligarquías del momento de las repúblicas oligárquicas del momento de las repúblicas oligárquicas es recibido con gloria, y todo este saber jurídico penal domina hasta mediados del siglo pasado. En realidad, en el siglo pasado había habido varios gobiernos 
populares que habían debilitado bastante a nuestras oligarquías vernáculas. Y después de la Segunda Guerra Mundial, ya tan racistamente nadie hablaba, aunque seguían pensándolo pero sabían que no lo debían decir. En consecuencia el discurso se derrumbaba por todos lados. Y bueno, los penalistas dijeron ¿dónde vamos a buscar a algo nuevo porque nos quedamos sin base? Y van a Alemania - que es dónde está más desarrollado, más elaborado- y desde entonces empezamos a traer todas las teorías alemanas que ahora citamos, y las tramos dramáticamente como si fueran neturas - y no son neutras, no son neutras para nada-.

Trajimos, lo que llamaban el causalismo, si ¿y qué autor trajimos? Y trajimos a un señor Edmund Mezger ¿quién fue Edmund Mezger? Fue el teórico neokantiano que justificó las peores leyes del nazismo. Trajimos después a Welzel -si, ya al dolo lo cambiamos...si- , pero ¿quién era Welzel? ¿y por qué hacía eso? Lo hacía porque era la época de Konrad Adenauer, se sanciona la Constitución de 1949, pero también se podía bajar de nuevo la constitución - no había Tratados de Derechos Humanos-, entonces Welzel dice... no un momento acá tiene que haber un límite al legislador, el legislador no puede inventar cualquier cosa, por eso se va para el lado del realismo para ponerle un cierto límite y acotar la arbitrariedad del legislador penal.

Ahora se pone de moda Claus Roxin, por ejemplo, que es un neokantiano liberal, si...está bien ¿Pero qué representa ideológicamente? Produjo escritos a lo largo de muchos años, y después hace su tratado juntando trabajos parciales que había hecho y arma el Tratado completo por el 2000, pero lo venía trabajando 30 años antes. Es el ideólogo de la Alemania post reconstrucción, de la Alemania Social Demócrata, de la época de Willy Brandt. Él había trabajado en el Proyecto Alternativo Alemán, que por cierto sostiene... cuidado "fíjense que por la elevación del nivel de vida estamos suprimiendo las causas del delito" en consecuencia el delito es causa residual y ese delito residual es resultado - más bien- de causas individuales, y entonces hace un sistema vicariante que permite reemplazar 
pena por medida de seguridad y tratamiento porque el delito es predominantemente resultado de factores individuales. Esta es una ideología propia de los años 70, 80 de Alemania, de Willy Brandt, la Alemania Social Demócrata.

Y después viene la reunificación Alemana, se vuelve la capital a Berlín, se termina con la República Democrática Alemana, y eso coincide con la caída del muro. Y eso permite una cierta migración de Europa Oriental hacia Alemania, países muy pobres de Europa Oriental - rumanos, etc.- que le causa una alarma tremenda a los alemanes que se asustan y entonces viene una explicación de tipo funcionalista de Günter Jakobs. Nada de esto - bueno o malo, cada uno tendrá sus ideas- es políticamente aséptico, somos nosotros que le quitamos el contenido, lo despolitizamos al traerlo. Entonces ha llegado el momento de pensar - en esto como en otras tantas cosas- dejémonos de copiar a los alemanes, imitemos a los alemanes. Hagamos construcciones dogmáticas teniendo en cuenta nuestra realidad social es como hacer un puente. Para hacer un puente vamos a contratar a los mejores ingenieros, lo mejor que haya para hacer el puente pero ¿Dónde hay que hacer el puente? ¿Para qué sirve el puente? Y ¿Qué capacidad debe tener? Eso lo decidimos nosotros. Esa es la cuestión frente a la que nos encontraos en este omento, es decir la construcción de un derecho, y una dogmática... construir un sistema., la constitución de un sistema viene desde antes que Rudolph Von Ihering sistematizara el método. En definitiva desde que empezaron los estudios de derecho en Italia desde hace 1000 años, que empezaron a teorizar nuestros bisabuelos. El espíritu del sistema estaba, lo que uno quiere es construir un sistema del cual se puedan deducir decisiones coherentes, decisiones coherentes, eso no lo podemos olvidar, no lo podemos evitar. Cuidado, dejar de lado la construcción de sistema, dejar de lado la dogmática, significa caer en el romanticismo. El romanticismo es muy tentador, es sumamente tentador. Si yo me pusiera en este momento a decir mirando fijo a la televisión "dejémonos de lado estas cosas, estos libros antiguos, y de leer 
alemanes y vayamos a ver lo que es el sentimiento del gaucho y del hombre que trabaja con la herramienta" -debe haber unos cuantos idiotas que me aplauden... no me caben dudas-, estoy entrando a la irracionalidad, estoy abriendo un campo de arbitrariedad que no voy a poder cerrar nunca.

La dogmática - el método-, es el único método que nos puede proveer cierta racionalidad en la contención del poder punitivo, en la solución de conflictos... sí. Pero siempre y cuando seremos racionales, y seremos eficaces en la solución de conflictos, en la medida en que tengamos en cuenta realidad social en dónde se desarrollan los conflictos y en dónde se ejerce el poder punitivo. Cuando perdemos eso de vista, lamentablemente nos perdemos en una dogmática que solo sirve para legitimar en el mejor de los casos actitudes burocráticas de los jueces, en el peor de los casos el lawfare.

Celebrar el décimo número de una revista de esta naturaleza y que se llama Derechos en Acción es decir, lucha por el derecho, es altísimamente estimulante. Efectivamente, lo es.

Es un momento de regresión de derechos humanos, es un momento de regresión de la política, el poder ya no lo tienen los políticos, el poder lo tienen corporaciones trasnacionales. Generar sociedades con un 30\% de incluidos y un $70 \%$ de excluidos, tiene consecuencias sumamente particulares que no podemos dejar de tener en cuenta cuando utilizamos el derecho. 